\title{
Coral Sand Solidification Test Based on Microbially Induced Carbonate Precipitation Using Ureolytic Bacteria
}

\author{
Md. Nakibul Hasan Khan ${ }^{1, *}$, G. G. N. N. Amarakoon ${ }^{1}$, \\ Suguru Shimazaki ${ }^{1}$ and Satoru Kawasaki ${ }^{2}$ \\ ${ }^{1}$ Graduate School of Engineering, Hokkaido University, Sapporo 060-8628, Japan \\ ${ }^{2}$ Faculty of Engineering, Hokkaido University, Sapporo 060-8628, Japan
}

Artificial beachrock, formed by coral sand solidification through microbially induced carbonate precipitation (MICP), could provide coastal protection instead of concrete structures, and would be eco-friendly as well as help minimize costs. The present study was conducted to solidify coral sand through the MICP method by using an ureolytic bacterium (Parahodobacter sp.) isolated from peripheral beachrock. The goal was to obtain a sample with an unconfined compressive strength (UCS) of $20 \mathrm{MPa}$ or more. We also aimed to examine the growth characteristics of this bacterium in the culture medium ZoBell2216E, which is commonly used for marine bacteria. In order to determine the suitability of the MICP test, growth properties of the microbial strain were observed under various culture conditions. A sand solidification test with MICP was carried out in a syringe as well as a PET cylinder. The strength of the resulting specimens was measured with the needle penetration test. The specimen solidified up to $20 \mathrm{MPa}$ of the estimated UCS after 21 days of curing. For optimum growth of the bacterium, $1.0 \mathrm{~g}$ of the culture was added to $100 \mathrm{~mL}$ culture media and incubated with shaking at $160 \mathrm{rpm}$. The preferred final concentration in solidification promoting solution of both urea and $\mathrm{CaCl}_{2}$ was $0.5 \mathrm{M}$, with bacterial cell densities of $10^{9} \mathrm{CFU} / \mathrm{mL}$. In order to efficiently induce solidification, the optimum $\mathrm{pH}$ was 7.0 or higher, and $\mathrm{Ca}^{2+}$ concentration was maintained at $1.0 \mathrm{~g} / \mathrm{L}$. The results were enhanced by re-injecting the culture solution when the $\mathrm{pH}$ and $\mathrm{Ca}^{2+}$ concentrations in the specimen were not in the ideal ranges indicated above.

[doi:10.2320/matertrans.M-M2015820]

(Received May 11, 2015; Accepted July 7, 2015; Published August 21, 2015)

Keywords: coral sand, solidification, microbially induced carbonate precipitation, beachrock, unconfined compressive strength, Pararhodobacter $s p$

\section{Introduction}

Coastal erosion has long been a significant problem globally, typically due to anthropogenic changes along the coastline, and it poses a hazard for people residing in these areas. Erosion of the sandy shore is often used to refer to changes in the coastline due to the collapse of the sediment balance. In order to prevent, or at least minimize damage from erosion, a combination of various structures and processes has been traditionally used, including embankments, revetments, jetties, artificial reefs, offshore breakwaters, and sand bypassing. ${ }^{1)}$

In order to cope with the increase in costs related to the maintenance and management of concrete structures, the use of inexpensive alternative materials should be considered. To minimize a lot of environmental problems associated with cement grouting, in recent years, microbially induced cement formation technics have been developed for ground permeability control and reinforcement. ${ }^{2-5}$ ) This process, the biological action for ground improvement, is called "biogrouting". ${ }^{6}$ ) Therefore, we focused on alternative materials to replace beachrock to reduce lifecycle costs associated with the currently employed methods. Beachrock forms much more quickly than other sedimentary rocks and is composed of coastal sediments that have been cemented together mainly by $\mathrm{CaCO}_{3}$, within the intertidal zone. ${ }^{7}$ By using the processes that solidify beach sand, we hypothesized that we could create a highly durable artificial beachrock that would be comparable in efficacy to the existing concrete structures.

Various factors have been considered in the formation of beachrock. Among them, Danjo and Kawasaki (2014), ${ }^{8)}$

*Corresponding author, E-mail: hasannakibk@gmail.com focused on the possibility of promoting solidification by microbial processes, specifically urea decomposition by microorganisms. Ureolytic bacteria and urea was used to precipitate calcium carbonate for bio-cementation. ${ }^{9,10)}$ In our study, we utilized the microbially induced carbonate precipitation (MICP) method with a new bacterial species in beach (coral) sand which relies on the microbial metabolism of urea that generates carbon dioxide and precipitates $\mathrm{CaCO}_{3} .{ }^{11)}$ This low environmental impact method was assessed to determine its efficiency as an alternative means to alleviate coastal erosion. In order to create an artificial rock, the present study was conducted with the following two purposes:

(1) To solidify coral sand, the goal was to obtain specimens with an unconfined compressive strength (UCS) of $20 \mathrm{MPa}$ or more, through the MICP method using ureolytic bacteria isolated from peripheral beachrock.

(2) To examine the growth characteristics of the microbial strain of ureolytic bacteria used in the experiment, and obtain growth curves of these bacteria in various culture conditions.

\section{Materials and Methods}

\subsection{Absorbance measurement}

\subsubsection{Materials}

The test bacterium was Pararhodobacter sp., an ureolytic bacterium isolated from the soil near beachrock in Sumuide, Nago, Okinawa, Japan. This microbial strain (a gram stain of the bacterium is shown in Fig. 1) was isolated from soil samples using artificial seawater (Akuamarine, Yashima Drug Company, Osaka, Japan) (Table 1). The microbial strain was cultured on ZoBell2216E medium (polypeptone $5.0 \mathrm{~g} / \mathrm{L}$, 


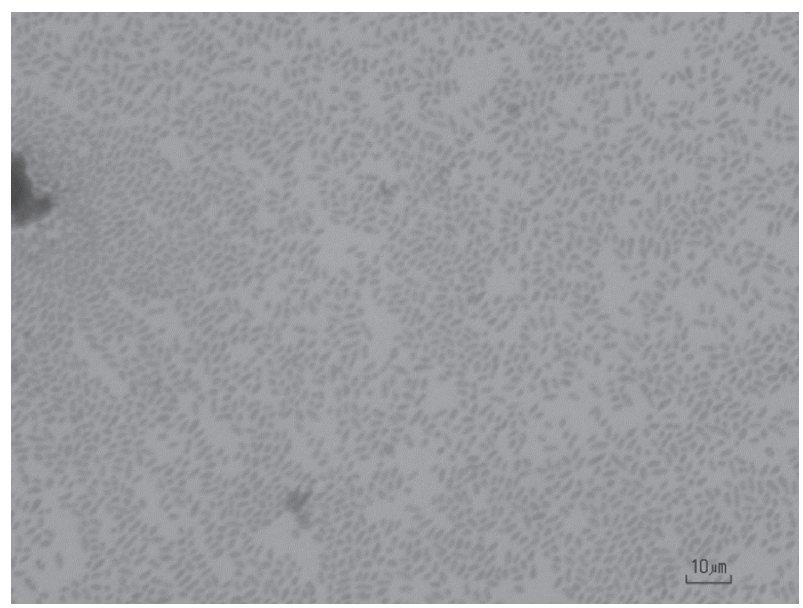

Fig. 1 Gram staining of Pararhodobacter sp.

Table 1 Composition of artificial seawater.

\begin{tabular}{lr}
\hline \multicolumn{1}{c}{ Reagent } & $\mathrm{g} / 20 \mathrm{~L}$ \\
\hline $\mathrm{MgCl}_{2} \cdot 6 \mathrm{H}_{2} \mathrm{O}$ & 222.23 \\
$\mathrm{CaCl}_{2} \cdot 2 \mathrm{H}_{2} \mathrm{O}$ & 30.7 \\
$\mathrm{SrCl}_{2} \cdot 6 \mathrm{H}_{2} \mathrm{O}$ & 0.85 \\
$\mathrm{KCl}$ & 13.89 \\
$\mathrm{NaHCO}_{3}$ & 4.02 \\
$\mathrm{KBr}$ & 2.01 \\
$\mathrm{H}_{3} \mathrm{BO}_{3}$ & 0.54 \\
$\mathrm{NaF}$ & 0.06 \\
$\mathrm{NaCl}$ & 490.68 \\
$\mathrm{Na}_{2} \mathrm{SO}_{4}$ & 81.88 \\
\hline
\end{tabular}

yeast extract $1.0 \mathrm{~g} / \mathrm{L}$ and $\mathrm{FePO}_{4} 0.1 \mathrm{~g} / \mathrm{L}$, in artificial seawater, $\mathrm{pH} 7.6 \sim 7.8$ ), which is often used for growth of marine bacteria.

\subsubsection{Methods}

The bacterial strain was cultured in liquid medium under various conditions. The change in cell density over time for each culture condition was quantified by measuring the absorbance (optical density) of the suspension using a spectrophotometer at $600-\mathrm{nm}$ wavelength $\left(\mathrm{OD}_{600}\right) .{ }^{12,13)}$ For each culture condition, the absorbance was read and the viable cell count was determined using the plate dilution method simultaneously. The correlation between the results of the viable cell count and the absorbance measurements was examined to determine the reliability of the absorbance measurement. Thus, we could estimate the number of bacteria under each condition. ${ }^{14)}$ Finally, the growth curve of the microbial strain in each culture condition was obtained to investigate the effects of various conditions on bacterial growth.

\subsubsection{Experimental conditions}

In order to shorten the total time for culturing the bacterial strain used in the experiment, the following three conditions were set up and analyzed, with respect to previous study. ${ }^{1)}$

(1) The initial mass of the microbe when added to the liquid culture medium was varied: $0.01 \mathrm{~g}, 0.1 \mathrm{~g}$, or $1.0 \mathrm{~g}$ (the previously used mass was $0.1 \mathrm{~g}$ ).

(2) The volume of liquid culture media was varied: 100 $\mathrm{mL}, 150 \mathrm{~mL}$, or $200 \mathrm{~mL}$ (as opposed to the previously

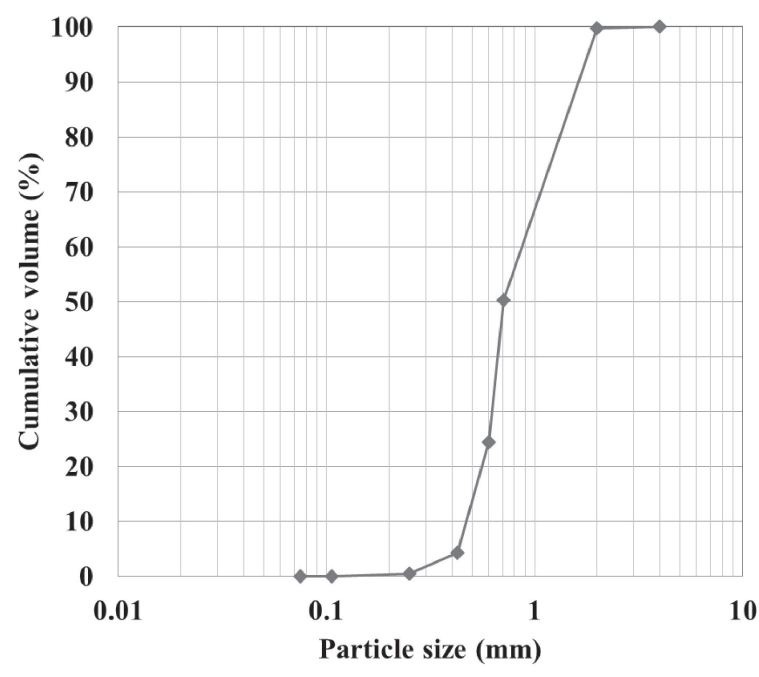

Fig. 2 Particle size distribution of coral sand.

used volume of $100 \mathrm{~mL}$ ).

(3) The shaking speed at the time of culture was varied: $80 \mathrm{rpm}$ and $160 \mathrm{rpm}$ (the previously used speed was $80 \mathrm{rpm})$.

\subsection{MICP test in a syringe \\ 2.2.1 Materials}

Pararhodobacter sp. and coral sand (the grain size distribution of the coral sand is shown in Fig. 2) from Okinawa, Japan, were used for the syringe solidification test. In addition, artificial seawater (Table 1) was used to recreate similar conditions to those in which the original beachrock was formed.

\subsubsection{Methods}

First, the bacterium was grown under various experimental conditions listed above (using different weights of cells and volumes of media). This culture, ZoBell2216E culture solution, was shaken for 2 days at $30^{\circ} \mathrm{C}$. Then, $40 \mathrm{~g}$ of coral sand, dried at $110^{\circ} \mathrm{C}$ for at least 2 days, was placed in a $35 \mathrm{~mL}$ syringe (diameter $2.5 \mathrm{~cm} \times$ height $7 \mathrm{~cm}$ ). Subsequently, $16 \mathrm{~mL}$ of the culture medium (ZoBEl12216E) and $20 \mathrm{~mL}$ of the solution for consolidation (this was the composition, mainly urea and $\mathrm{CaCl}_{2}$, used for all of the various test conditions) was sequentially injected into the syringe and drained, leaving approximately $2 \mathrm{~mL}$ of solution above the surface of the sand. The solution for consolidation was then injected and drained once a day. The $\mathrm{pH}$ values and $\mathrm{Ca}^{2+}$ ion concentrations of effluents, solidification solution taken from the lower part of each sample, were measured every 3 days. The state of the syringe solidification test is shown in Fig. 3(a). After 14 days of curing, the UCS of the specimen was estimated using a needle penetration device (SH-70, Maruto Testing Machine Company, Tokyo, Japan).

\subsubsection{Experimental conditions}

To determine the effect of various conditions on the UCS of specimen, the following conditions were used over a test period of 14 days: the mass of the bacterial culture used was $0.01 \mathrm{~g}, 0.1 \mathrm{~g}$, or $1.0 \mathrm{~g}$; the concentrations of urea and $\mathrm{CaCl}_{2}$ (solution for consolidation) used were $0.3 \mathrm{M}, 0.4 \mathrm{M}$, or $0.5 \mathrm{M}$. The standard conditions $(0.1 \mathrm{~g} / 0.3 \mathrm{M})$ were the same as those used by Inagaki et al. (2011). ${ }^{15)}$ 


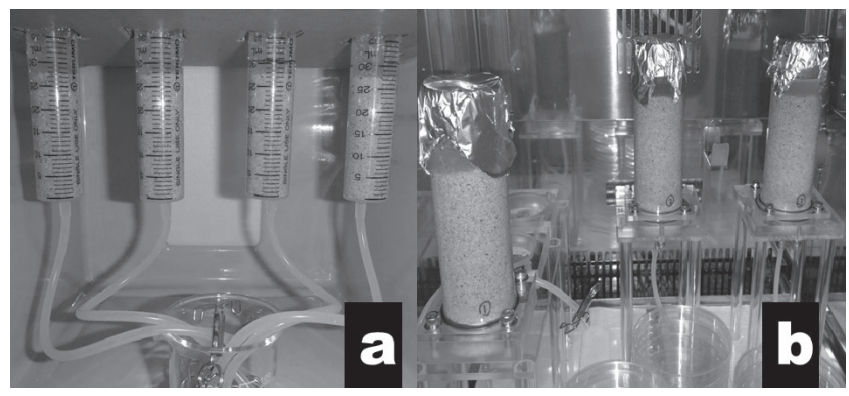

Fig. 3 State of sand solidification tests in (a) the syringe and (b) the PET cylinder.

\subsection{MICP test in PET cylinders \\ 2.3.1 Materials}

The materials (bacteria, coral sand, and artificial seawater) used in the column solidification test were identical to those used in the syringe test described in section 2.2.1.

\subsubsection{Methods}

Column tests were conducted based on the method that recorded the highest UCS in the syringe. Methods used for the column test were identical to those used for the syringe test, except that a PET cylinder (diameter $5 \mathrm{~cm} \times$ height $10 \mathrm{~cm}$ ) served as the column. The following components were added sequentially to the column: $300 \mathrm{~g}$ dried coral sand, $120 \mathrm{~mL}$ of culture medium, and $150 \mathrm{~mL}$ of the solution for consolidation. The state of the column test is shown in Fig. 3(b). UCS was measured after 14 and 21 days of curing using the same device as the syringe. In addition, the cell density of the bacterial populations in the specimens in this column was determined using ZoBell2216E agar medium after 7 days of curing at $30^{\circ} \mathrm{C}$.

\subsubsection{Experimental conditions}

Considering the effect of conditions on the UCS of a specimen, two test conditions were utilized: one with normal (similar to syringe) and other without normal, the re-injection of the culture solution. For normal test condition, the mass of the microbe (culture solution) was $0.01 \mathrm{~g}$ or $1.0 \mathrm{~g}$ and urea and $\mathrm{CaCl}_{2}$ (solution for consolidation) were each at a final concentration of $0.5 \mathrm{M}$. The test period was 14 days. In the experiment where the culture solution was re-injected, the mass of the bacteria (culture solution) was $1.0 \mathrm{~g}$, and urea and $\mathrm{CaCl}_{2}$ (solution for consolidation) concentrations were $0.5 \mathrm{M}$ each. The test period was either 14 days, or 21 days, or 28 days with the culture solution repeatedly injected every 7 days. Both the $\mathrm{pH}$ and $\mathrm{Ca}^{2+}$ ion concentrations were measured daily which were obtained from the outlet of solidification solution in each sample.

\section{Results}

\subsection{Absorbance measurement}

The absorbance values, which indicate the growth rate of the bacterium, under various culture conditions are described below, under the two main aspects that were carefully examined.

\subsubsection{Importance of the volume of the culture solution and shaking speed}

The results obtained using various volumes of culture media $(100 \mathrm{~mL}, 150 \mathrm{~mL}$, and $200 \mathrm{~mL})$ and shaking speeds

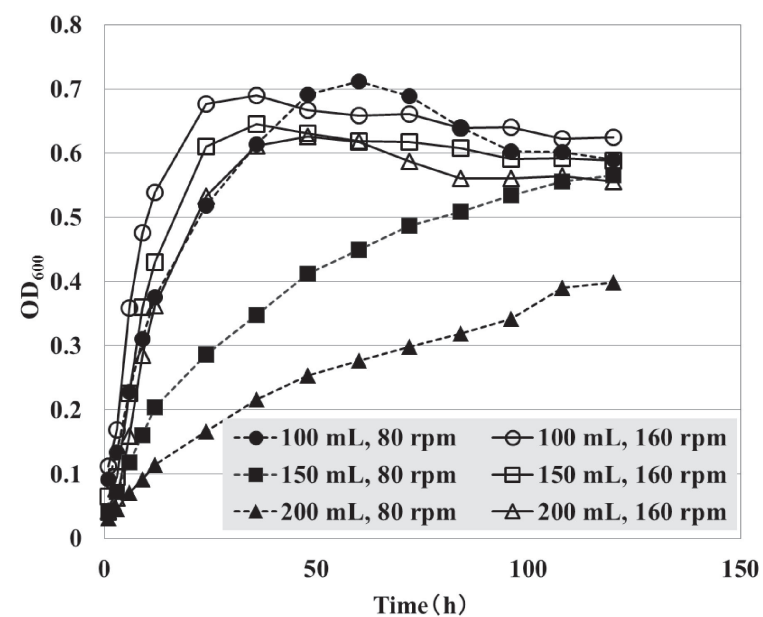

Fig. 4 The absorbance measurement results focused on the amount of liquid medium and shaking speed.

$(80 \mathrm{rpm}$ and $160 \mathrm{rpm})$ are shown in Fig. 4. With regard to shaking at $80 \mathrm{rpm}$, the absorption values for all three experiments increased with a decrease in the volume of culture medium. Moreover, the experiments conducted at $160 \mathrm{rpm}$ revealed similar results as those at shaking speeds of $80 \mathrm{rpm}$. The variance in absorbance per volume of liquid medium was significantly less at $160 \mathrm{rpm}$; however, the absorbance values measured in $150 \mathrm{~mL}$ and $200 \mathrm{~mL}$ volumes at $80 \mathrm{rpm}$ experiments were drastically different. In addition, the time required to reach the maximum absorbance was between 24 and $48 \mathrm{~h}$ in $100 \mathrm{~mL}$ shaken at $160 \mathrm{rpm}$.

\subsubsection{Importance of the amount of culture and culture media utilized}

In Fig. 5, the differences due to varying amounts of bacterial culture (0.01-1.0 g) added to the liquid culture medium are demonstrated; $200 \mathrm{~mL}$ of the liquid medium was used. We found that increasing the amount of microbial strain added to the liquid medium increased the absorbance. A significant difference was observed in the absorbance at the end of the culture period when $0.5 \mathrm{~g}$ or $1.0 \mathrm{~g}$ culture was originally added. When comparing the volume of liquid medium used, we found that the lower the volume, the greater the absorbance value. As the absorbance for $0.1 \mathrm{~g}$ of microbial strain in $200 \mathrm{~mL}$ culture solution is lowest but the same amount of microbial strain in $100 \mathrm{~mL}$ culture solution gave greater absorbance than above all (Fig. 5). Ultimately, $100 \mathrm{~mL}$ volume resulted in a higher final absorbance reading than did $200 \mathrm{~mL}$ volume.

\subsection{MICP test in syringe}

We decided to use $100 \mathrm{~mL}$ of the liquid culture medium and shake the culture at $160 \mathrm{rpm}$, which would provide ideal absorbance readings as well as result in optimum bacterial growth. The $\mathrm{pH}$ and temperature for the optimal growth of the bacteria was $7.0-8.5$ and $30-40^{\circ} \mathrm{C}$, respectively. The above conditions were implemented for all conditions during the solidification test.

\subsection{1 pH of effluent}

The $\mathrm{pH}$ of all specimens during the test period tended to be lower than the $\mathrm{pH}$ at the beginning of the experiment (Fig. 6). However, when $1.0 \mathrm{~g}$ of the culture was added, regardless of 


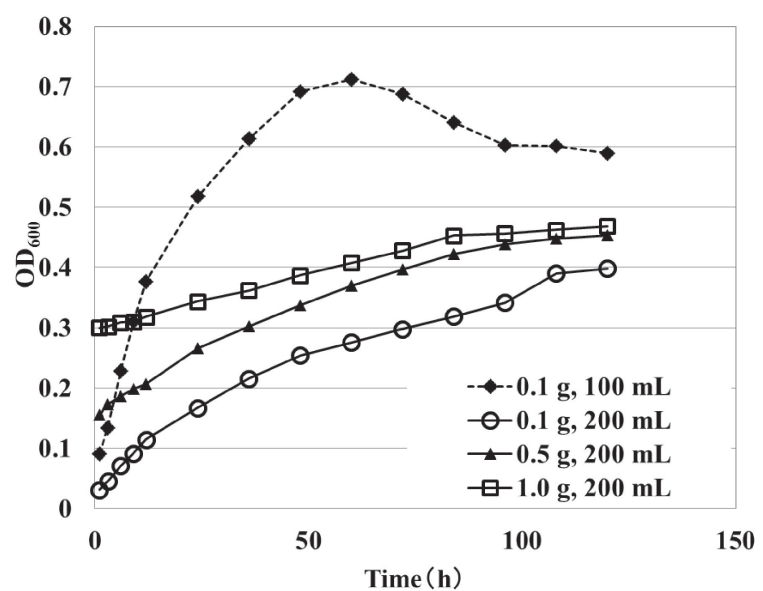

Fig. 5 The absorbance measurement results focused on the amount of microbial strain added and liquid medium.

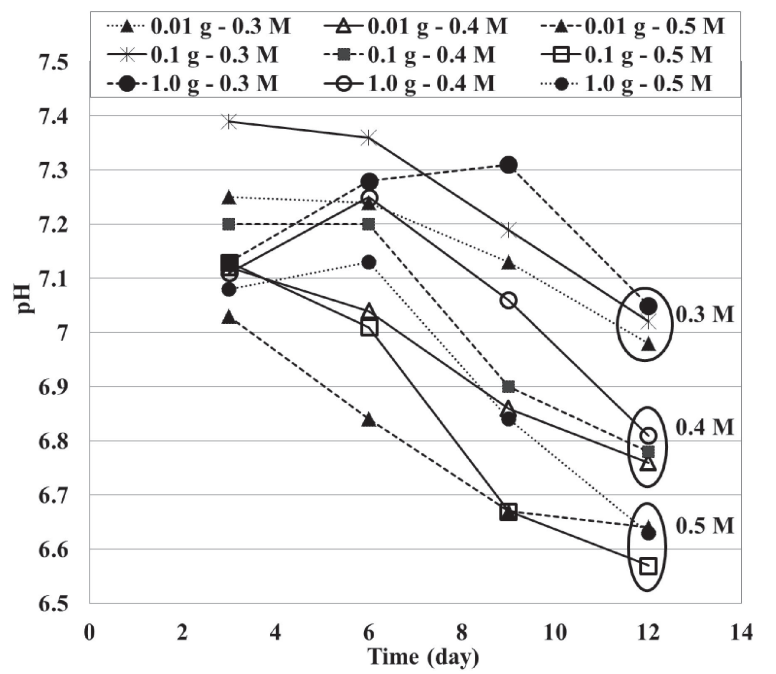

Fig. $6 \mathrm{pH}$ of the effluent over time course in the nine different test cases in the syringe.

the amount of urea and $\mathrm{CaCl}_{2}$ added, the $\mathrm{pH}$ increased from days 3 through 6 . Measurement of the $\mathrm{pH}$ was stated from day 3 in all cases of the experiment.

\subsection{2 $\mathrm{Ca}^{2+}$ concentration}

The effect of the $\mathrm{Ca}^{2+}$ concentration on the effluent in nine test cases is shown in Fig. 7. $\mathrm{Ca}^{2+}$ concentration was at $2.0 \mathrm{~g} / \mathrm{L}$ or less in all cases when measured after 3 days. Like $\mathrm{pH}$, the $\mathrm{Ca}^{2+}$ concentration also measured from 3 rd day in all cases throughout the experiment. After the growth period, the $\mathrm{Ca}^{2+}$ concentration tended to increase markedly when the urea and $\mathrm{CaCl}_{2}$ solution added was at $0.4 \mathrm{M}$ and $0.5 \mathrm{M}$. The concentration of $\mathrm{Ca}^{2+}$, when the $0.3 \mathrm{M}$ urea and $\mathrm{CaCl}_{2}$ solution were used, did not change over time and continued to be consumed until the $\mathrm{Ca}^{2+}$ was present in concentrations above $10.0 \mathrm{~g} / \mathrm{L}$. In the experimental conditions using $0.4 \mathrm{M}$, the $\mathrm{Ca}^{2+}$ concentration $(0.01 \mathrm{~g} / 0.4 \mathrm{M})$ an increase was observed after 7 days, and the consumption of $\mathrm{Ca}^{2+}$ at the 12-day time point was reduced to approximately $10.0 \mathrm{~g} / \mathrm{L}$. On the other hand, the most dramatic increase in $\mathrm{Ca}^{2+}$ concentration was in the experimental conditions using $0.5 \mathrm{M}(0.01 \mathrm{~g} / 0.5 \mathrm{M})$, during which the consumption of $\mathrm{Ca}^{2+}$ at the 12-day time point was reduced to $7.0 \mathrm{~g} / \mathrm{L}$.

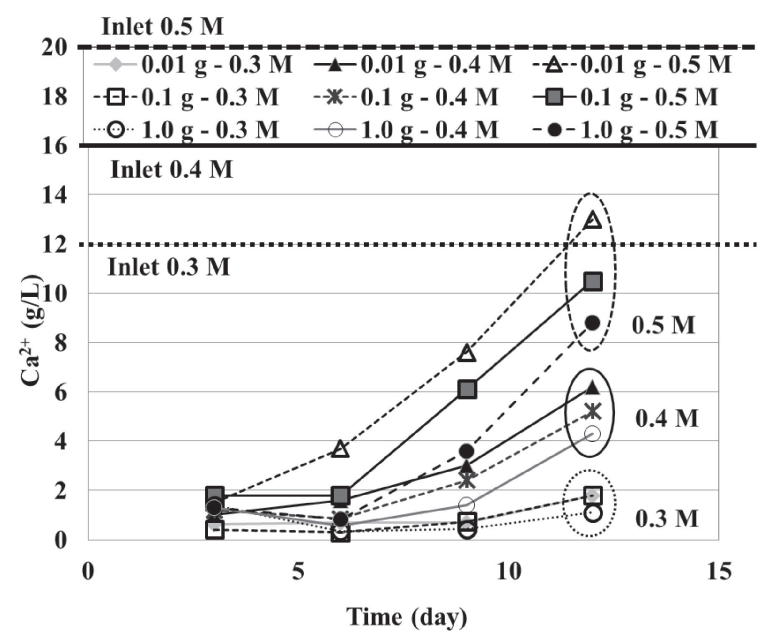

Fig. $7 \mathrm{Ca}^{2+}$ concentration of effluent over time in nine different test cases in the syringe.

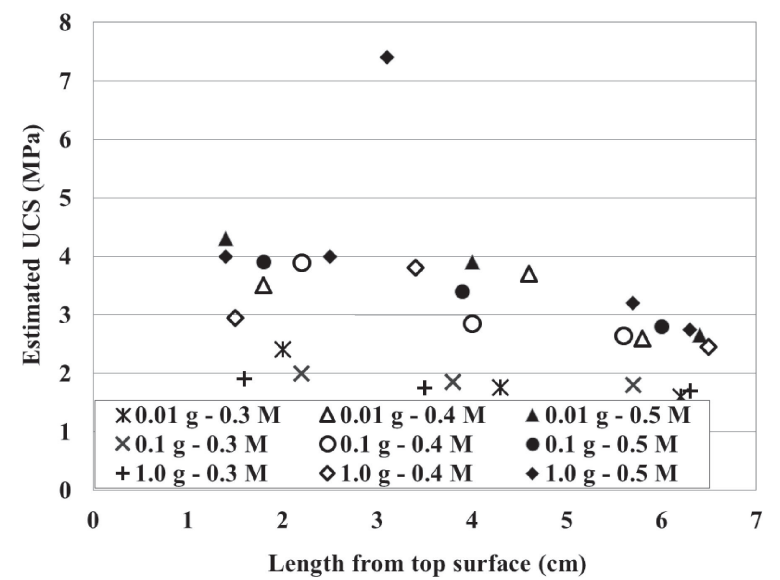

Fig. 8 Needle penetration test results of specimen in syringe under various test conditions.

\subsubsection{Estimated UCS values}

The summarized results of the needle penetration test for each case are shown in Fig. 8. The estimated UCS value of the $0.3 \mathrm{M}$ urea and $\mathrm{CaCl}_{2}$ experiments was approximately $2 \mathrm{MPa}$, regardless of the added amount of culture added. In the cases of $0.4 \mathrm{M}$ and $0.5 \mathrm{M}$, the estimated UCS value tended to be higher than when the solution was $0.3 \mathrm{M}$. When the amount of bacterial strain added was $0.01 \mathrm{~g}$ and $0.1 \mathrm{~g}$ for both $0.4 \mathrm{M}$ and $0.5 \mathrm{M}$ urea and $\mathrm{CaCl}_{2}$ solutions, the UCS showed 3 4 MPa. The specimens were significantly solidified in all experiments using $0.5 \mathrm{M}$, where the estimated UCS value at some points exceeded $7 \mathrm{MPa}$. The estimated UCS value tended to decreases from the top to the bottom of the specimen in both the case of $0.4 \mathrm{M}$ and $0.5 \mathrm{M}$ urea and $\mathrm{CaCl}_{2}$ solutions.

\subsection{MICP test in PET cylinders}

The solidification promoting solution of urea and $\mathrm{CaCl}_{2}$ yielded better results at a concentration of $0.5 \mathrm{M}$ using the syringe test, where the highest UCS was obtained. Therefore, in the column experiment a concentration of $0.5 \mathrm{M}$ was used for all test cases. 


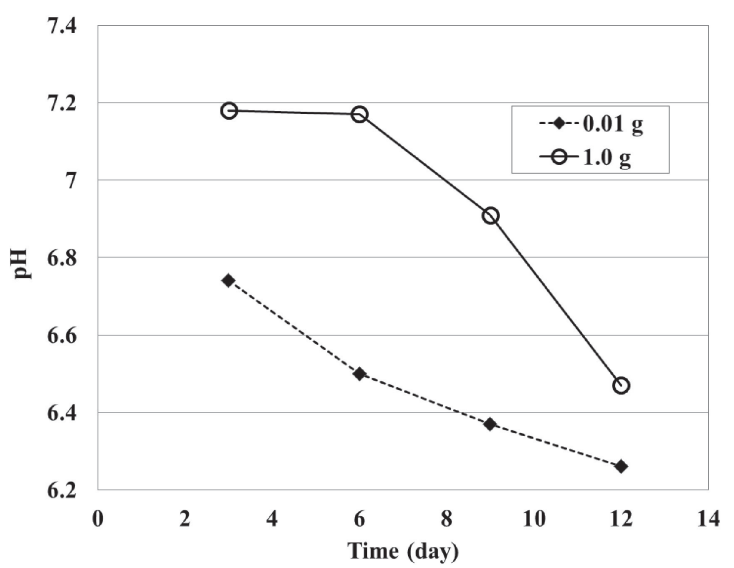

Fig. 9 Changes in the $\mathrm{pH}$ of the effluent over time in the column test.

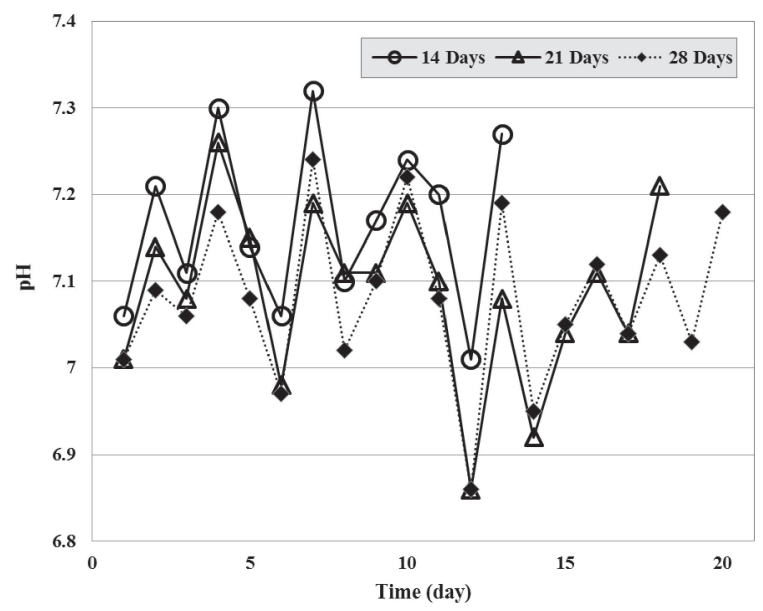

Fig. 10 Changes in the $\mathrm{pH}$ of the effluent over time in different test cases in the re-injection column test.

\subsection{1 pH of effluent}

The $\mathrm{pH}$ of effluent of various test conditions are shown in Fig. $9(0.01 \mathrm{~g}$ and $1.0 \mathrm{~g}$ of bacterial culture and $0.5 \mathrm{M}$ urea/ $\mathrm{CaCl}_{2}$ solution) and Fig. 10 (re-injection of $1.0 \mathrm{~g}$ of bacterial culture and $0.5 \mathrm{M}$ urea $/ \mathrm{CaCl}_{2}$ solution). The $\mathrm{pH}$ over the time course when $1.0 \mathrm{~g}$ culture was added, demonstrated a similar tendency in column as was seen in the syringe (Fig. 6 and Fig. 9). Alternatively, when $0.01 \mathrm{~g}$ of bacterial culture was added, the $\mathrm{pH}$ of the column remained about 0.3 less than that measured in the syringe, and the rate of decrease of the $\mathrm{pH}$ tended to be similar to that of the syringe (Fig. 6 and Fig. 9). However, the $\mathrm{pH}$ in the re-injected column test remained between approximately 7.0 7.3, and did not continue to decrease (Fig. 10).

\subsection{2 $\mathrm{Ca}^{2+}$ concentration}

The measurement results of the $\mathrm{Ca}^{2+}$ concentration in the effluent in various cases $(0.01 \mathrm{~g}$ of bacterial culture with $0.5 \mathrm{M}$ urea $/ \mathrm{CaCl}_{2}$ and $1.0 \mathrm{~g}$ of bacterial culture with $0.5 \mathrm{M}$ urea $/ \mathrm{CaCl}_{2}$ ) are shown in Fig. 11. The culture solution of $1.0 \mathrm{~g}$ of bacterial culture was re-injected every 7 days as one time, two times and three times in the 14 days, 21 days, and 28 days curing periods of the samples respectively (Fig. 12). The $\mathrm{Ca}^{2+}$ concentration revealed a trend similar to the results seen with the syringe. Specifically, in the case when $1.0 \mathrm{~g}$ culture was added, the $\mathrm{Ca}^{2+}$ concentration increased over

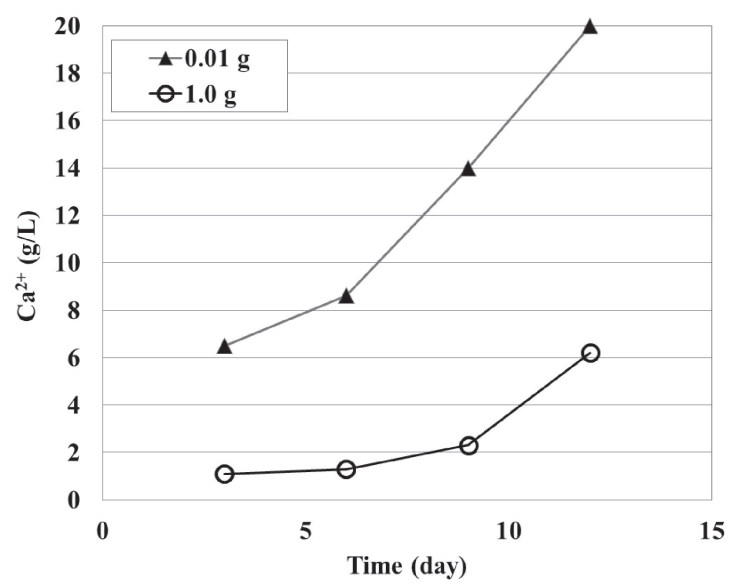

Fig. 11 Changes of $\mathrm{Ca}^{2+}$ concentration over time on the effluent in the column test.

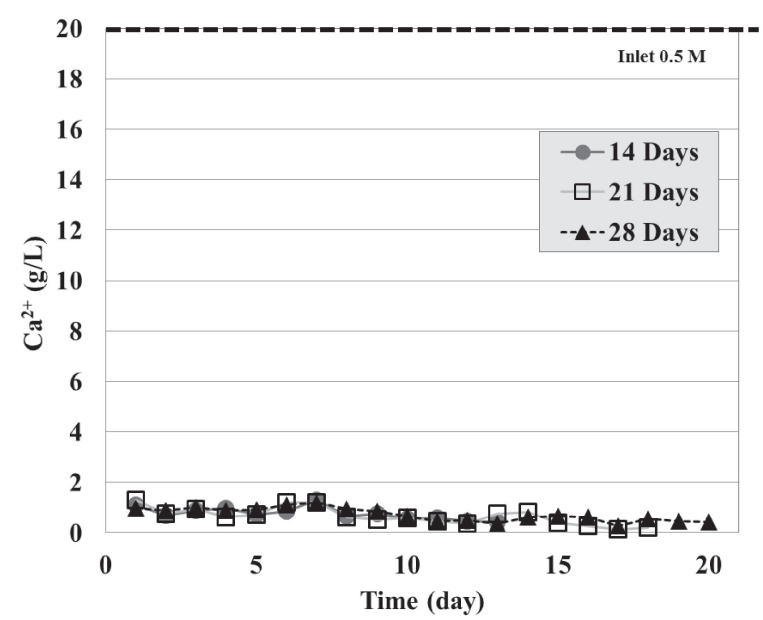

Fig. 12 Changes of $\mathrm{Ca}^{2+}$ concentration over time on the effluent in the reinjection column test.

time (Fig. 11). In the instance when $0.01 \mathrm{~g}$ of bacterial culture was added, the increase of the $\mathrm{Ca}^{2+}$ concentration was accelerated more in the column than in syringe (Fig. 7 and Fig. 11) which was not predicted to be the result of the experiment. The $\mathrm{Ca}^{2+}$ concentration in the re-injection test cases was approximately constant during the entire test period (Fig. 12). Overall, in the standard tests the $\mathrm{Ca}^{2+}$ concentration increased from the beginning to the end of the experiment, which was not seen when cultures were reinjected.

\subsubsection{Estimated UCS value}

The results of the needle penetration test for each specimen in various test conditions, $0.01 \mathrm{~g}$ of bacterial culture with $0.5 \mathrm{M}$ urea $/ \mathrm{CaCl}_{2}$ and $1.0 \mathrm{~g}$ of bacterial culture with $0.5 \mathrm{M}$ urea $/ \mathrm{CaCl}_{2}$ are shown in Fig. 13, as well as the experiment wherein the culture $(1.0 \mathrm{~g}$ of bacterial culture in $0.5 \mathrm{M}$ urea/ $\mathrm{CaCl}_{2}$ ) was re-injected at 7 days, 14 days and 21 days in the 14 days, 21 days and 28 days of curing periods of the samples respectively (Fig. 14). The estimated UCS values of the both test cases of $0.01 \mathrm{~g}$ of bacterial culture with $0.5 \mathrm{M}$ urea/ $\mathrm{CaCl}_{2}$ and $1.0 \mathrm{~g}$ of bacterial culture with $0.5 \mathrm{M}$ urea/ $\mathrm{CaCl}_{2}$, harbored a tendency to decrease from top to bottom (Fig. 13). In the re-injected 14 days test period, the UCS was 


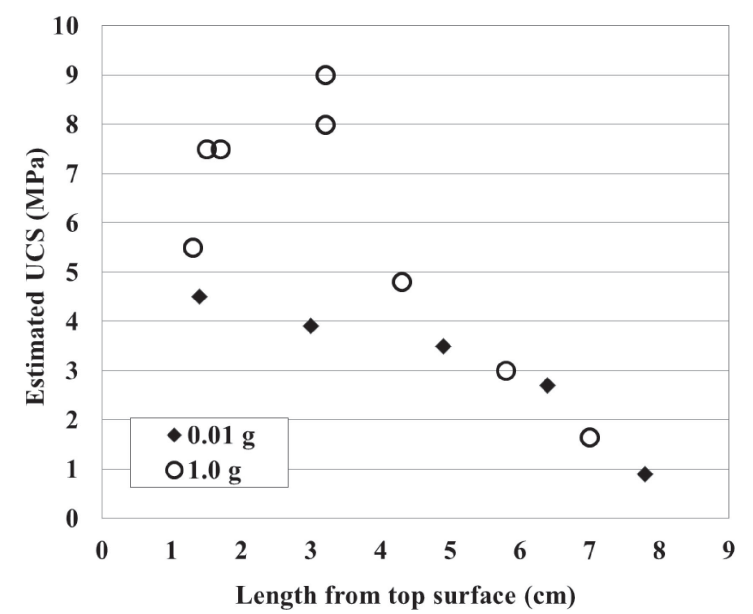

Fig. 13 Needle penetration test results of specimens of each case in the column test.

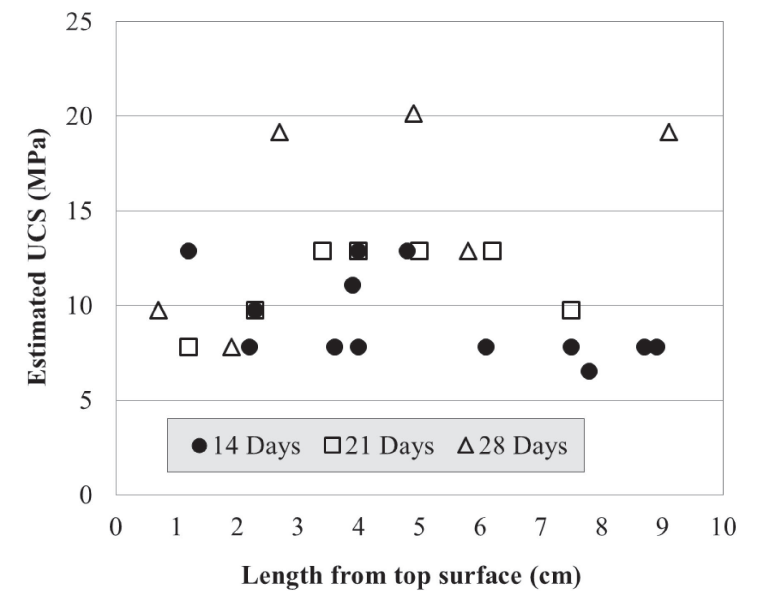

Fig. 14 Needle penetration test results of specimens in different cases in the re-injection column test.

approximately $8.0 \sim 12.0 \mathrm{MPa}$ in the upper half of the container and $6.5 \sim 8.0 \mathrm{MPa}$ in the lower half. The UCS demonstrated a decreasing tendency from the upper half to the lower half of the column (Fig. 14). In the experiment where the culture was re-injected at the sample of 21 days curing, the UCS was approximately $13 \mathrm{MPa}$ at all locations in the central portion of the specimen, the upper and lower part demonstrated between 7.8 9.7 MPa (Fig. 14). However, the re-injection experiment at the sample of 28-day curing time point harbored a value exceeding the results previously obtained (Fig. 8 and Fig. 13) from the upper, middle and bottom of the column. In particular, the estimated UCS value in the central portion harbored a value of $20.2 \mathrm{MPa}$ (Fig. 14). Therefore, the UCS value of the with and without re-injection culture conditions showed a higher tendency in the column experiment than in the syringe experiment. Specimen of immediately after removal of the column test is shown in Fig. 15.

\subsubsection{Stress-strain curve of the specimen}

The stress-strain curve for each experiment was obtained by implementing the uniaxial compression test (Fig. 16). The fracture strain of the column test case of $0.01 \mathrm{~g} / 0.5 \mathrm{M}$ was $1.06 \%$ and for $0.1 \mathrm{~g} / 0.5 \mathrm{M}$ was $1.13 \%$, the difference was

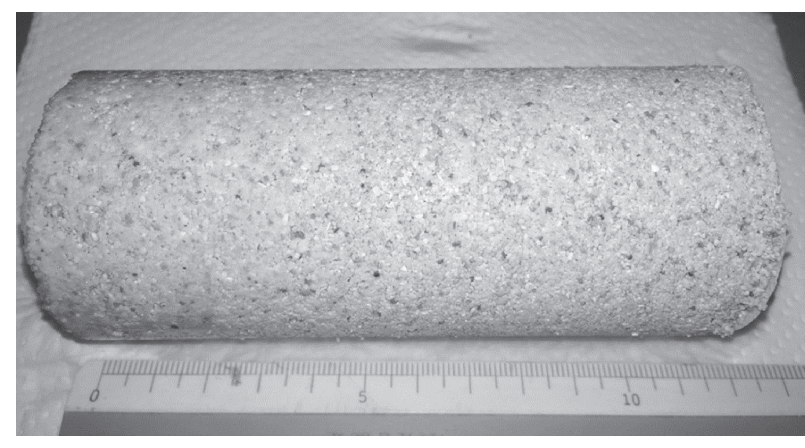

Fig. 15 Appearance of specimens taken from column test (photo left specimen top).

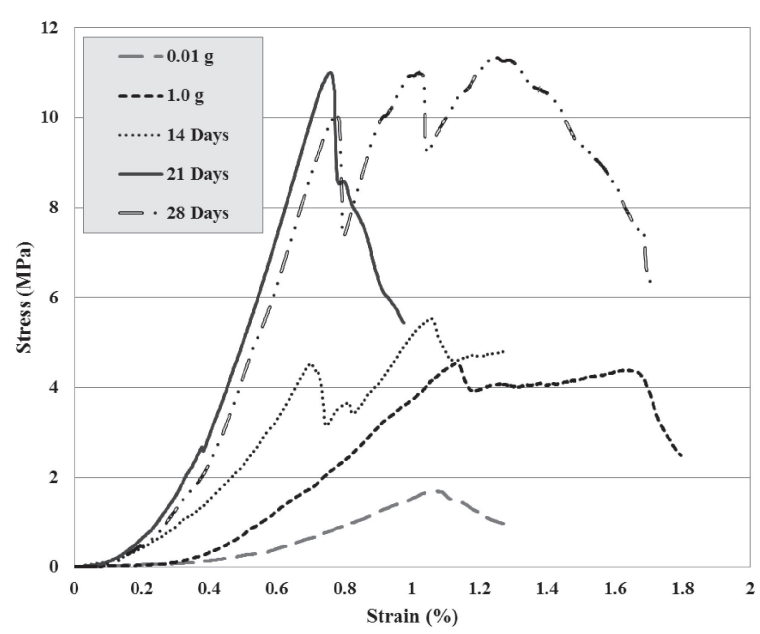

Fig. 16 Stress-strain curve obtained from specimens of each case in the column test.

less than $0.1 \%$. Moreover, the strain reached approximately $1.7 \%$ until rupture of the specimen, with the test case $0.1 \mathrm{~g}$, the stress was maintained for approximately $4 \mathrm{MPa}$. In the reinjection column test, the UCS value showed an increasing trend. In addition, fracture strains of $1.06 \%, 0.76 \%$, and $1.25 \%$ were observed at the samples of 14 days at 21 days at 28 days curing periods respectively.

\subsubsection{Viable cells of the solidified specimen in the columns}

The viable cell count was measured after the end of the solidification test with samples taken from the top, central and bottom of each specimen, as is shown in Fig. 17. The top of the specimen harbored the largest bacterial density in all cases except that at 21 days, which harbored a constant gradient of bacterial cell density from the top to the bottom. At the $1.0 \mathrm{~g} / 0.5 \mathrm{M}$ case, the number of bacteria increases from the middle to the bottom of the specimen. Only in the instance where $0.01 \mathrm{~g} / 0.5 \mathrm{M}$, does the number of bacteria significantly decrease from the top to the middle and bottom.

\section{Discussion}

\subsection{Growth properties of Pararhodobacter sp. in various culture conditions}

\subsubsection{Effects of the amount of microbial strain added}

When more bacterial culture was added at the beginning of the experiment, the maximum value of the absorbance was 


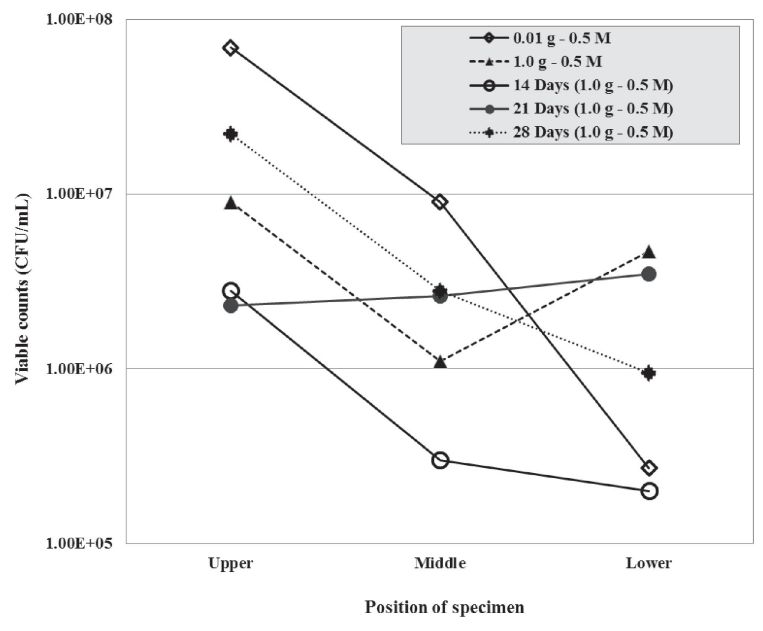

Fig. 17 Number of viable bacteria in each specimen after the end of the column solidification test.

obtained (Fig. 5). Since the absorbance measurement was based on the turbidity of the culture solution, this result is expected. However, as the same concentration of nutrients is available in the media, we predicted that the difference in cell densities would reach a peak regardless of the amount of cells initially added. Unlike the expected test result, regardless of the amount of microbial strain added, the absorbance was nearly constant at approximately $80-100 \mathrm{~h}$ (Fig. 5). It is difficult to explain the actual cause of the above result; the possible reasons could lie in the nutrients, source of dissolved oxygen and medium, but these factors were not examined. However, when the medium composition was the same, the absorbance read at the various time points were comparable regardless added amount of microbial strain. This result is considered advantageous as it allows for the artificial control of the cell density in the medium used.

4.1.2 The effect of the amount of liquid medium utilized

With the increase in medium volume, the absorbance was decreased regardless of the speed shaken or amount of microbial strain added (Fig. 4 and Fig. 5). However, as shown in Fig. 5, the concentration of the culture at the initial stage increased, and the subsequent increase rate was smaller at $0.1 \mathrm{~g} / 200 \mathrm{~mL}$, however the maximum value in absorbance was also drastically different. These results, when compared to other conditions, reflected that increasing the volume of the medium and microbial strain simultaneously, resulted in lowering the absorbance. However, these problems were solved by increasing the shaking speed. In Fig. 4, the resulting growth curves were improved with increasing the shaking speed. This indicates that increasing the shaking speed, and more thoroughly mixing the culture liquid, influences the increase in cell density. In this case, it appears that the nutrient source (oxygen) was rapidly and homogeneously dispersed in the culture. If homogenization of nutrients and increased supply of oxygen in the culture fluid is assumed important, it is also explains why a decrease in absorbance is observed when the volume of the culture media is increased.

\subsubsection{Effect of shaking speed}

The absorbance increased with a faster shaking speed, the maximum value of the absorbance was obtained when shaken at $160 \mathrm{rpm}$ in comparison to $80 \mathrm{rpm}$ (Fig. 4). The increase in shaking speed was considered to be effective in shortening overall time needed for the experiment to take place. When shaken at $160 \mathrm{rpm}$, the absorbance peaked approximately $24 \mathrm{~h}$ after the start of the culture, indicating that the three-day growth is not necessary in the future.

\subsection{MICP test in syringe}

\subsubsection{Role of $\mathrm{pH}$ and $\mathrm{Ca}^{2+}$ concentrations}

As can be gathered from Fig. 6 and Fig. 7, the $\mathrm{Ca}^{2+}$ concentration increases when the $\mathrm{pH}$ lowers. The diminution of urea hydrolysis with decreasing cell density is a potential cause of $\mathrm{pH}$ reduction. Therefore, in the specimen, if there are high concentrations of urea or $\mathrm{CaCl}_{2}$ at the beginning, the amount of carbon dioxide produced by urea decomposition does not reduce $\mathrm{Ca}^{2+}$ consumption, in fact, eventually $\mathrm{Ca}^{2+}$ concentration could have increased. Alternatively, the precipitation of $\mathrm{CaCO}_{3}$ for MICP begins at the cell surface of bacteria, ${ }^{16,17)}$ microbial strains induce precipitation of $\mathrm{CaCO}_{3}$ at a crystal nucleus.

\subsubsection{Relationship between $\mathrm{Ca}^{2+}$ concentration and the estimated UCS in the specimen}

From Fig. 8, in the case of the concentration of $0.4 \mathrm{M}$ and $0.5 \mathrm{M}$ solutions in the promotion of sand solidification solution of urea and $\mathrm{CaCl}_{2}$, the estimated UCS value of the specimen ranged from 3 to $4 \mathrm{MPa}$; the intensity distribution tended to decrease from the top to the bottom of the specimen. In both cases, the $\mathrm{Ca}^{2+}$ concentration in the effluent demonstrated a tendency to increase in the latter half of the study period (Fig. 7). The collected effluent was estimated to have a $\mathrm{pH}$ and $\mathrm{Ca}^{2+}$ concentration of the lower part of the specimen. Furthermore, since this microbial strain was cultured in aerobic conditions, it is possible that oxygen concentration played a role in microbial strain activity. Since it can be considered that the bottom of the specimen approaches anaerobic conditions, the lower portion of the specimen may demonstrate reduced microbial strain activity of this microbial strain when compared to the top of the specimen. Therefore, the estimated UCS value of the specimen was expected to decrease from the top to bottom. On the other hand, from Fig. 8 , in the case of $0.3 \mathrm{M}$ urea/ $\mathrm{CaCl}_{2}$, the estimated UCS values of the specimen were approximately $2 \mathrm{MPa}$. In addition to the concentration of the urea and $\mathrm{CaCl}_{2}$, the amount of $\mathrm{Ca}^{2+}$ in the effluent was generally constant throughout the test period (Fig. 7). The concentration of $\mathrm{Ca}^{2+}$ in the original solidification promoting solution was consumed nearly $90 \%$ by the precipitate as $\mathrm{CaCO}_{3}$. Therefore, it was expected that the estimated UCS values of the specimen should also remain constant, which is consistent with the results obtained above.

\subsection{MICP test in PET cylinders}

\subsubsection{Impact of a scale-up to the relationship of $\mathrm{pH}$ and $\mathrm{Ca}^{2+}$ concentrations in the specimen}

The results demonstrated in Fig. 9 and Fig. 11, indicate that if the re-injection of the culture was not performed during the study in the column solidification test, both the $\mathrm{pH}$ and $\mathrm{Ca}^{2+}$ concentrations in the effluent decreased and increased, respectively. This trend was observed regardless of the cell density of the liquid culture injected. These results are 
similar to the tendency that was also observed in the syringe solidification test. However, if the re-injection of the culture is completed during the study, the $\mathrm{pH}$ was approximately 7.0 7.3, and the $\mathrm{Ca}^{2+}$ concentration was constant at approximately $1.0 \mathrm{~g} / \mathrm{L}$ throughout the course of the experiment (Fig. 10 and Fig. 12). For this reason, in the scale-up from the syringe to the column, the impact on the relationship of $\mathrm{pH}$ and $\mathrm{Ca}^{2+}$ concentrations of the specimen was considered negligible.

\subsubsection{Impact of the scale-up on the strength of specimen}

As demonstrated in Fig. 13, the estimated UCS value revealed tendency to decrease from the top to the bottom of the specimen, which is similar to the results obtained with the syringe test (Fig. 8). However, this reduction of the UCS was remarkable when compared to that in the syringe; the results of the $1.0 \mathrm{~g} / 0.5 \mathrm{M}$ experiment were approximately two times greater for the UCS on the top of the column (Fig. 8 and Fig. 13). In the re-injection test results of the column (Fig. 14), in particular at sample of 28 day, the estimated UCS value was double that recorded using the standard test. In addition, we also observed variation in solidification, which had increased the UCS value regardless of the position of the specimen, indicating that the specimen was heterogeneous and lacked problems in solidification prior to scale-up. However, at the sample of 21 day time point, the specimen was considered to be uniformly solidified when compared to other cases (Fig. 14). For this reason, there was a possibility that cell density in the specimen was constant.

\subsubsection{Effect of the cell density on the estimated UCS value in the specimen}

With regard to the relationship of cell density to the specimen position at the end of the column test, the number of bacteria from the specimen top to bottom tended to be reduced in all cases except the 21-day time point (Fig. 17). From the Fig. 13, Fig. 14, and Fig. 17, the correlation can be observed between the estimated UCS value of each position and the number of bacteria present. In fact, at the top, the cell density was higher and the specimen was more solidified. However, the same correlation in the samples of 21 and 28 days' time points was not seen. In contrast, the number of bacteria revealed a consistent trend regardless of the specimen position in the sample of 21 day time point. In this case, since the cell density was constant, the precipitation of $\mathrm{CaCO}_{3}$ was homogeneous, and the solidification of the specimen proceeded homogeneously. Alternatively, in the test cases with $1.0 \mathrm{~g}$ of bacterial culture at the samples of 14 day and 28 day time points, the development of solidification in specimens, in particular near the bottom, was heterogeneous.

\section{Conclusions}

As part of a process to create artificial rock, a solidification test on coral sand was conducted using local ureolytic bacteria. In this study, results demonstrated that the specimen solidified up to $20 \mathrm{MPa}$ UCS after 28 days of curing using a microbial strain of Pararhodobacter sp. Based on the findings from this study, for future attempts of the MICP method using this microbial strain to obtain the ideal conditions for solidification in the future, four suggestions are outlined below:

(1) To facilitate solidification in a short period, the urea and $\mathrm{CaCl}_{2}$ concentration should preferably be $0.5 \mathrm{M}$.

(2) When the urea and $\mathrm{CaCl}_{2}$ concentration of $0.5 \mathrm{M}$ is used, the viable cell count utilized should be at a concentration of $10^{9} \mathrm{CFU} / \mathrm{mL}$.

(3) For the well progress of solidification of the specimen, the $\mathrm{pH}$ in the specimen should be 7.0 or higher, and the $\mathrm{Ca}^{2+}$ concentration should be maintained at $1.0 \mathrm{~g} / \mathrm{L}$.

(4) When the $\mathrm{pH}$ and $\mathrm{Ca}^{2+}$ concentrations in the specimen are out of the above range, the process can be improved by injecting more of the culture again.

\section{Acknowledgements}

The authors gratefully acknowledge the support for this research provided, in part, by research grants from the Japanese Ministry of Education, Culture, Sports, Science and Technology, Grant-in-Aid for Scientific Research (No. 24300299), and the East Nippon Expressway Company Limited, Grant for Technology Research (No. 64-1).

\section{REFERENCES}

1) T. Danjo, S. Kawasaki, S. Shimazaki and K. Koizuka: Proc. Int. Symposium on Geomechanics from Micro to Macro (2013) pp. 15211526.

2) V. S. Whiffin, L. A. Van Paassen and M. P. Harkes: Geomicrobiol. J. 24 (2007) 417-423.

3) W. De Muynck, N. De Belie and W. Verstraete: Ecol. Eng. 36 (2010) $118-136$.

4) J. T. DeJong, B. M. Mortensen, B. C. Martinez and D. C. Nelson: Ecol. Eng. 36 (2010) 197-210.

5) M. P. Harkes, L. A. Van Paassen, J. L. Booster, V. S. Whiffin and M. C. M. Van Loosdrecht: Ecol. Eng. 36 (2010) 112-117.

6) L. A. Van Paassen, M. P. Harkes, G. A. Van Zwieten, W. H. Van der Zon, W. R. L. Van der Star and M. C. M. Van Loosdrecht: Proc. 17th Int. Conf. on Soil Mechanics and Geotechnical Engineering, (2009) pp. 2328-2333.

7) T. Danjo and S. Kawasaki: Int. J. GEOMATE 5 (2013) 633-638.

8) T. Danjo and S. Kawasaki: Mater. Trans. 55 (2014) 493-500.

9) M. Akiyama and S. Kawasaki: Eng. Geology 125 (2012) 119-128.

10) M. Akiyama and S. Kawasaki: Eng. Geology 137-138 (2012) 29-39.

11) V. S. Whiffin, L. A. Van Paassen and M. P. Harkes: Geomicrobiol. J. 24 (2007) 417-423.

12) H. L. Ehrlich: Geomicrobiology, (Marcel Dekker, New York, 2002).

13) J. K. Fredrickson and M. Fletcher (ed.): Subsurface Microbiology and Biogeochemistry, (Wiley-Liss, Hoboken, NJ, 2001).

14) M. Fukue, S. Ono and Y. Sato: Soils Found. 51 (2011) 83-93.

15) Y. Inagaki, M. Tsukamoto, H. Mori, S. Nakajima, T. Sasaki and S. Kawasaki: Japan Geotech. J. 6 (2011) 157-167.

16) J. T. DeJong, B. M. Mortensen, B. C. Martinez and D. C. Nelson: Ecol. Eng. 36 (2010) 197-210.

17) W. De Muynck, N. De Belie and W. Verstraete: Ecol. Eng. 36 (2010) $118-136$. 